\title{
Remodel, a game for strategic issues in industrial $R \& D$ and production planning
}

\author{
K.F. Mulder (a), C.M. Ree (b), H.A.J. Mulder (b)
}

a. Delft University of Technology, Faculty of Technology and Society, Technology Assessment, De Vries van Heystplantsoen 2, NL-2628 RZ Delft, The Netherlands, telephone: +31-15-2781043, fax +31-15-2783177, e-mail karel.mulder@wtm.tudelft.nl

b. University of Groningen, Chemistry Shop, Nijenborgh 4, NL-9747 AG Groningen, telephone: +31-50-3634132, fax +31-50-3634100,e-mail:c.m.ree@chem.rug.nl, h.a.j.mulder@chem.rug.nl

\begin{abstract}
This chapter describes the game 'Remodel'. It has been developed in the Netherlands. It focuses on strategic decisions in regard to technological innovation and environmental regulation. The game stimulates the awareness of science and engineering students for the organisational and political context of their future professions.
\end{abstract}

\section{Keywords}

Games, Technological Innovation, Strategy, Environmental Policy 


\section{INTRODUCTION}

The Dutch university system was reformed in the 1980s. The university curricula for science and engineering were reduced from about 5.5 years to 4 years. In this process, courses on philosophy, psychology and social sciences were often abolished. Key staff members generally supported these courses. However, their influence weakened in the universities that became increasingly market-oriented. As a result, reflective courses disappeared from the curriculum. Ever since, science and engineering students received very little training in how to deal with the political, economical, ethical and social/cultural aspects of their future professions. Although many employers of scientists and engineers had previously been rather sceptical of the critical content of "Science, Technology and Society" courses, they started realising that these courses had contributed to the scientists and engineers social understanding and social skills. As a result of the critique of employers, universities tended to give more attention these subjects in the 90s.

In 1991 Groningen University set up a course for undergraduate science students on 'Industrial Innovation and the Environment'. This course teaches the main environmental threats and the contribution of new technology to their mitigation. However, many barriers and risks of various kinds (economical, cultural, political, and organisational) have to be overcome in order to realise the potential environmental benefits of innovation. These issues cannot be dealt with just by lectures and the study of text books; bringing new technologies into being also involves persuading other people in order to get their support, being able to delegate problems, dealing with regulatory agencies, etc. In 1991-92, therefore, we developed the social simulation game Remodel to enable students to feel what it was all about. It was successfully used in the spring of 1992. Later, the game was also used for engineering students at Delft University of Technology, and environmental management students at Tilburg University.

At all three universities, Remodel is played at the end of theoretical courses that mainly focus on (industrial) technological innovation, environmental targets and constraints, environmental management and environmental policy. Thus the participants in the game have studied some theory and cases before. Remodel should contribute to their skills to apply that knowledge in practice.

\section{THE REMODEL GAME}

\subsection{Basic Idea}

The aim is to teach science students to recognise the social processes in technological development and to give them skills to deal with its non-technical and nonscientific elements. These subjects can be, and actually are, reflected in lectures on environmental, social, organisational, economical and policy issues in science and technology. However, we are convinced that students learn more when they not only learn to reproduce textbook wisdom, but really feel the tensions in actual innovations and the friction between self-interest, group interest and political convictions, economics and the environment, impartial administration and active 
government interference. To have the participants really go through these conflicts, we decided not to develop a role-game (that is, a game played according to role prescriptions) but to develop a simulation game (that is, a game that creates a setting in which participants can develop their goals and roles in interaction). Van der Meer (1983) showed that, under the right circumstances, participants very rapidly create their own world within given institutional structures.

Once the game has started, the level of 'inclusion' of the participants, that is, the degree to which they actually act according to the norms and values of the institutional unit to which they belong during the game, rises very rapidly.

Remodel focuses on strategic decision-making regarding industrial production, technological innovation and global environmental issues. The main actors dealing with these issues are corporate executives, research managers and market analysts within industrial corporations, governmental agencies, environmentalists, the 'general public' (through the media) and eventually academic scientists and politicians. In order to achieve a dynamic game it is important that multiple relationships exist between these actors. If not, individual actors could easily decide just to make their own policy without paying attention to anybody else.

A carefully designed social structure of various 'checks and balances' therefore has to be designed to create a need for negotiations and compromises. In the context of a game, this system of 'checks and balances' is hard to achieve for those actors who are guided not primarily by economical incentives but by 'credibility', such as environmentalists and politicians. We therefore simplified the set of actor groups participating in the game:

Corporation

Executive Board

Department for Research \& Development

Department for Marketing \& Sales

(Supervisory Board)

Union Representative (=employee of Marketing \& Sales)

Government

Environmental agency

(President)

Journalist

The game manager plays the role of President. The President is allowed to interfere when the environmental agency is totally overruled by the industrial lobbyists. Usually, the President is hardly active during the game. The Supervisory Board, also a role played by the game manager, has the same function. In general, it only plays a role in preventing an early bankruptcy. In that case, the game manager might let the corporation survive at a mere subsistence level. Each actor group (except for the journalist and the President) is made up of three or four individuals, each having a different position (chief, expert on...) within their group. At the same time some actors have specific positions, such as union representative. 


\subsection{Designing a social structure by the control of money and information}

For a good game, a social structure is needed offering each participant at least a small chance of influencing the course of the game. Therefore, more than one kind of authority is necessary. We take money and information as basic elements to design the social structure of the game. Control of money can be used to build hierarchic positions, while control of information (by expert groups) or information flows (by the media) can be used to counteract hierarchic control. The game is designed to be played in annual cycles. At the end of the year the corporations make their decisions on investments, production, etc., based on government measures taken during the year. These decisions are fed into the computer, which calculates the corporations' financial results. The computer program simulates the ups and downs in the markets of the industrial products involved. The computer program only administers the game, and does not have a major influence on the course of affairs.

The length of the year is fixed at 40 minutes. This period is deliberately chosen to be rather short, as we want to ensure that no player ever feels superfluous. On the other hand, shortage of time forces the participants to depend on the judgements of others instead of working out everything for themselves. Moreover, some stress contributes to the realism of the game. The end of the game is always sooner than announced, as we want to prevent 'end of the world' effects, like spending all available money, making one last gamble that would bring the company enormous success, etc. In general, about 6-8 years are played. Practice has shown that this is generally enough to experience the processes for which the game is intended.

\section{Money}

Within the corporation the financial flows are controlled by the executive boards, and are therefore a means of maintaining hierarchic control. The treasurer of the executive board can draw money from the corporate bank account, which is kept by the computer program. This money can be used to pay wages. Each year the executive boards determine the wages. They receive a proposal for the wages in the first year of the game; in this proposal the lowest wages are about $25 \%$ of the highest wages.

The game money is of real importance. All participants have to pay for their lunch and drinks right from the start; that is, the corporation has to be profitable, otherwise the participants will 'starve'. In many cases, the executive boards pay bonuses during lunchtime. Of course, there has to be something worthwhile for participants to spend excess game money. In general we supply something expensive that becomes a status symbol. Sometimes, charity is introduced to pay for some participants' lunch. In practice, the game managers prevent participants having nothing to eat.

During the game's introduction participants often ask whether bribery is allowed. The game manager then answers, 'No, of course not, what else do you expect the President to answer?' So bribery can occur and it is often admitted afterwards that it has occurred, but on a very limited scale. 


\section{Information}

Modern corporations are not (solely) controlled by hierarchic power based on the control of finance. Various groups within the corporation have a certain bargaining power because of their specific resources (specific expertise, relations, etc.). Since none of the participants in the game has specific expertise, the corporate hierarchy is balanced by a flow of specialised information from the computer towards the marketing and $R \& D$ departments. The result is that executives, marketers and researchers, who each have rather different orientations in evaluating corporate decisions (cf. the famous studies of Lawrence \& Lorsch, 1967), have rather balanced bargaining positions in regard to corporate decision-making on the course of technological innovation.

Another important aspect of the game is the regulation of contacts. As the participants are often acquainted with each other, some rules must be maintained to protect the pre-given social structure from the effects of pre-existing social ties. If not, the participants are inclined to get together, discuss all matters, share all the information, and change the simulation into a game of 'all against the computer'. Hence three rules are strictly enforced:

- all communication between the various groups is in writing, and is transferred by mail system

- meetings are very limited and only possible with the approval of the game manager

- the simulation will not be paused once it has started; that is, lunch, coffee and tea are served at each group's quarters.

Naturally, larger meetings are not prohibited when they are really necessary in the course of the game, for example a strike meeting or an environmental conference.

\section{Regulatory agency}

The governmental agency's budget depends partly on the state of the economy. This means that it is a percentage of the corporate wages. The agency's regulatory power over industry is rather limited; only levies on production and a ban on the application of the industrial product in specific applications are allowed. Moreover, the agency has to announce all its measures at least six months in advance. It may withdraw the announced measures, but can never introduce measures that have not been announced. This means that the agency has only rude tools to steer this branch of industry. Moreover, it gets little information on the economic effects of its measures on the companies involved.

The early announcement of measures, and the lack of discrimination of these measures, implies that there is a strong incentive for the companies to negotiate and lobby. As a result, the agency is generally involved in many discussions with various parts of the corporations. Frequent topics of discussion are access to information and the effects of regulatory measures. Only on a few occasions does the simulation manager have to use his powers as President: either to enforce the agency to take action on the environmental issue, or to prevent it from shutting down this branch of industry right from the start. However, the agency often applies for a budget to subsidise research and development into new, clean products. 
These budgets are generally granted on condition that the agency submits a detailed project description and proves that the subsidies are covered by the levies on the 'dirty' products.

\subsection{Case}

\section{Environmental problem: CFCs - Ozone Hole}

The global environmental dangers that threaten our civilisation (such as global warming, decreasing bio-diversity, depletion of non-renewable resources, long-term health and reproductive effects of newly released chemicals, and military-conflictinduced disasters) are also generally the ones that are rather controversial, especially in the initial stages when the issues are first discussed.

We estimated that the actor groups we have defined in the game would probably be inclined to refuse to take action without strong evidence. Pressure to change would then necessitate strong government action, which in turn would depend on strong public support. Since we decided to focus our game on the industrial rather than the public part of this process, we looked for a case with scope for debate between government and industry, but with little scope for industry to refuse to take any action. The CFC (Chlorinated Fluoro-Carbons)/Ozone problem was excellent for our purposes. Moreover, this case was very well documented from an industrial economy/business study's perspective, i.e. by Manzer (1990), Moore (1990), Smith (1989) and, most usefully for our purposes, Forest Reinhardt (1989).

The starting point of Remodel is the CFC industry in 1974, when Molina and Rowland (1974) published their famous article claiming that CFCs, after being released into the atmosphere, deplete the ozone layer. The ozone layer filters out harmful ultraviolet radiation, and therefore its depletion might cause a rise in skin cancer and lower crop growth. However, at the time that Molina and Rowland formulated this relationship between the release of CFCs and ozone depletion, no empirical evidence existed that ozone depletion was actually occurring. Because of the availability of Smith and Reinhardt's data on the US, we chose to simulate imaginary US corporations and the real US Environmental Protection Agency (EPA), though with imaginary powers.

\section{Game decisions}

The decisions that the corporations have to take within the course of a year are varied. They have to decide:

- the number of plants for each CFC they produce (each plant has a fixed capacity)

- the marketing budgets for each CFC (to increase market share)

- the price levels for each CFC they produce

- process research (bringing down production costs)

- investment in $R \& D$ projects for new products

- (if enough $R \& D$ is done) the introduction of a newly developed product onto the market

- salaries and the withdrawals from the company's bank account 
For financial success it is crucial to have the plants run at (almost) maximum capacity. However, closing down plants as well as opening new ones is expensive, and it is therefore rather difficult to determine the right moment to adjust plant capacities. Conversion of a plant is possible and is cheaper than first closing it and later opening a new one. In fact, only the marketing department receives the information required to make these decisions. For the R\&D department similar considerations hold as to whether or not to invest in a research project.

The EPA can influence prices and demands by means of levies and regulations. Levies can be varied and can even be negative (e.g. a subsidy). Levies cause markets to decline and prices to fall. However, their effect is moderate as compared to the bans on specific applications that can be introduced: for example a ban on CFCs in spray cans causes an almost complete collapse of market demands and prices. Thus it would mean the end of the game if this ban were implemented right from the start. However, by first introducing levies, and announcing its intentions several years before, the EPA can introduce such a ban without necessarily bankrupting the industry.

As stated above, we do not instruct the participants to achieve a pre-given goal. We therefore tell them not to 'replay' the history with hindsight, but to start dealing with the given situation of uncertainty. We could have dealt with this problem by making the game purely imaginary. However, this could mean that participants would experience the game as less realistic. Moreover, in practice it turns out that most of the participants only vaguely know the historical course of events, and are only aware of the serious character of the ozone/CFC issue.

In the course of the game we had to change the historic course of events a little. In practice we cannot play more than 10 'game years' in a one-day run, and it was therefore important to change the dates of some historic events (the discovery of the ozone hole above the Antarctic, the Montreal Protocol) to include them in the game.

Initially the game simulated the interplay of one industrial company and the EPA. Later we realised that the element of competition was missing. In the game this was a problem particularly for the EPA; if the agency wanted to pursue a more active policy to encourage the replacement of CFCs by non-harmful compounds, it was solely dependent on the co-operation of one company. This company therefore had a very strong (and unrealistic) bargaining position towards the EPA. The introduction of a second company also enlivened the game by provoking intercompany competition.

\subsection{Practical arrangements}

\section{Computer use}

A computer model simulates demands for various types of CFCs and market prices. The model is based on extrapolations of data contained in Reinhardt's (1989) study. These show that the Molina and Rowland article significantly affected the market positions of two major CFCs. The third one, CFC 113, was hardly affected by the news as this compound was mostly sold to industrial users, that is the microelectronics industry, which was growing fast. 
The computer model uses several random factors. This is not just to make the program more realistic but also to avoid making the outcome of the game too easy to calculate. Since our participants are generally science or engineering students with great mathematical skills, we do not want them to try to calculate the algorithms of the software. All the same, one can observe a tendency among these students to try to beat the algorithms of the computer program. Random factors are therefore absolutely essential. However, as a consequence, the competition between the two CFC corporations is partially decided by chance.

In evaluating the game we use the computer program to show why loss of profit occurred, why companies have been financially successful and whether the government agency's policy has been successful, and we look at the environmental impact of all the actions. Often we observe that it is only at this stage that participants discover the logic of each other's actions.

\section{Preparation for the game}

Before the game each participant receives a general description of the game and of the actors who are included in it. Secondly, they also receive an information package describing the organisation or department in which they participate, and their main activities, and they receive some advice on the options open to them and the implications thereof. Each group has separate quarters, and they are urged to go there immediately after they receive their information packages. They study their information with colleagues and determine their strategy. Generally, Remodel really starts about 75 minutes after the start of the introduction.

Before playing the game many practicalities have to be arranged: nine more or less separate sets of quarters, coffee, lunches (and something 'expensive', like cakes), memos, decision and advice forms (to prevent people forgetting to deal with all the relevant issues), game money, paper, pencils, etc. An important task is the mail system. A game assistant is needed to deliver the mail. Altogether, the preparations for one run of Remodel generally take at least half a day if one has run the game before.

\subsection{Further adjustments to the game}

Lately we have been using a Local Area Network for the communication between participants . The results are very positive. Managing the game was generally a hectic job which use of the network made much easier. However, this way of playing necessitates many arrangements concerning computer hardware, connections, etc.

At the end of the game participants often get into a mood of trying to beat the computer jointly. In these circumstances the game manager has to terminate the game. A further adjustment of the game might therefore be to further increase the number of companies or to provide for more actors outside the corporations who could enhance the dynamics of the game, for example environmentalists, a second government agency (which, for example, aims to promote new technologies), an independent consulting firm and so on. This would, of course, make the game more

\footnotetext{
* We acknowledge the efforts of Patrick Jharap for helping to adjust the software for this version.
} 
realistic, but also more complicated. The preparation time needed would increase and practical barriers might be put up.

We are currently working on an Internet version of Remodel that provides a remote participation facility and includes more actors.

\section{LEARNING FROM REMODEL}

The game Remodel, in its various forms, has been run about 25 times, generally with 15 to 22 science and engineering students as participants. In general, role inclusion of the participants is very high: problems caused by participants who withdraw from the game virtually never occur. In the game motivation is high; the participants very soon take various initiatives that fit into the game, without being given any incentive to do so.

The game makes a profound impression on its participants. Although we did not perform any long-term evaluations of learning effects, it is our impression that, even after more than a year, most of the participants are able to recall exactly what happened during the game.

Students strongly prefer learning from their 'own experiences' to traditional teaching. The main learning effects in catchwords are: 'delegating responsibilities', 'decision-making under uncertainty', 'corporate responsibilities versus political convictions' and 'government- industry interdependencies'. We will deal with these issues separately:

\section{Delegating Responsibilities}

Most executives have problems in delegating responsibilities to their R\&D and Marketing Departments. They often try to re-calculate the recommendations given by these departments, which is futile since they do not have the detailed data required for such calculations. In the first rounds of the game, and also during later rounds if business is bad, the written correspondence often consists of demands for these data. Because of the time pressure in the game (decisions will have to be made at the end of the 'year', just as in real-life), there is simply no time for recalculation, even if the data are received and understood. Confidence in each other's capacities is also undermined by confusion of tongues or plain incomplete recommendations - both factors are aggravated by time pressure. The marketing and R\&D departments sometimes lose their trust in the executive board if their recommendations are not followed blindly. This is also a sign of fear of delegation; the executives have an overview over Marketing as well as $R \& D$ requirements, something that is not understood by these departments - especially if things go wrong for the company. Rumours instigated by the journalist often aggravate mistrust; for example, bribing is allowed so long as the game managers (as presidential authority) do not know about it; the journalist can spread rumours about it. Bribing does occur in the game.

Probably, this problem concerning delegating responsibility is specific to working with science and engineering students: their training consists of learning how to work out things for themselves. They do not learn how to allow others, better trained or equipped, to work out things for them. Dealing with deadlines 
neither forms part of their training; participants often expect the game manager to delay the game if they are not ready. Naturally this is refused. This attitude is probably caused by the academic way of dealing with problems: you simply take the time needed for a solution that meets the scientific criteria. The game teaches its participants to work towards a solution that can be reached with the means given, and within a given period.

\section{Decision-making under uncertainty}

A few aspects of decision-making under uncertainty are closely linked to the problems of delegating responsibility; each department has to base its decisions on its own - limited - data. The main aspect of understanding the problem of making decisions without complete scientific knowledge comes up during the game, when the EPA gets new reports (from the computer, or maybe even through the newspaper) on the state of the environment. The companies never know how long EPA measures will remain unchanged. Nor do their own R\&D departments have a complete overview of the state of the environment. The competitive element between the two companies increases uncertainty; when the other company develops a new product and successfully launches it on the market there is no reason why the EPA should not ban the CFC for which it is a substitute.

\section{Corporate responsibilities versus political convictions}

In the evaluations we ask the students if they developed any explicit (corporate) environmental policy. Almost always the answer is 'no'. The environment is seen as a cost factor; the company's mission is to make profits. Some companies had environmental programs as a derivative of economic motives, for example in order to have a strong negotiating position towards the EPA (the EPA can mediate to the President to get financial support for 'green product development').

\section{Interdependency of government and industry}

From time to time it turned out that the EPA had been bribed by company money; a civil servant's salary is lower than that of the average company employee. There are, however, also serious discussions, in which subsidies or loans can be given. In one game the participants even decided to organise a scientific conference with both companies and the EPA.

\section{Other learning effects}

Elements of a social ('prisoners') dilemma also emerged: when one company is pro-active and the other is reactive towards the environmental effects of CFCs the latter will gain more money when there is no strict environmental legislation. This happens because the latter company does not have to invest or pay levies on its CFC products. Only if both companies decide to act, they are both better off than in a situation where neither acts - provided that investing now is cheaper than paying levies in later years.

There are some social lessons for the participants of the game too. In most games, the executives keep their own salaries higher than those of their sub-ordinates in marketing and R\&D. However, inside each room, the wages were often equalled. Therefore, even the secretary of the executive board generally earns 
more than the marketing chief. There are not many complaints about this situation. From time to time executives can be seen to give away some of their money. Generally, however, they themselves eat most expensive. In one case, an excessive executive board lunch (while others could only pay for one sandwich) led to a strike. The lesson, however, seems to be that solidarity is substantial in the same room, but...

\section{REFERENCES}

Lawrence, P.J. and Lorsch, J.W. (1967) Organization and Environment. Harvard University, Boston.

Manzer, L.E. (1990) The CFC-Ozone Issue: Progress on the development of Alternatives to CFCs. Science, 249, 31-5.

Molina, M.J. and Rowland, F.S. (1974) Stratospheric sink for chlorofluormethanes: chlorine atom-catalysed destruction of ozone. Nature, 249, 810-2.

Moore, C.A. (1990) Industry Response to the Montreal Protocol. Ambio 19, 320-3.

Reinhardt, F. (1989) Du Pont Freon Products Division. Harvard Business School, Boston, case study 8-389-111.

Smith, N.C. (1989) Sealed air corporation: marketing impacts of eliminating CFCs. Harvard Business School, Boston, case study 9-589-107.

Van der Meer, F.B. (1983) Organisatie als spel: sociale simulatie als methode in onderzoek naar organiseren [Organisation as a game: social simulation as a method in organisational research], dissertation University of Twente, Enschede.

The authors wish to acknowledge the invaluable comments that the received from Ton Schoot Uiterkamp and Geert Vissers.

\section{BIOGRAPHY}

Karel Mulder is a lecturer in Technology Assessment at Delft University of Technology. In 1992, he obtained a doctorate in Management Studies. Karel Mulder is president of the Technology and Society Department of the Netherlands Royal Institute of Engineers (KIvI).

Karin Ree and Henk Mulder are the co-ordinators of the Chemistry Shop of the University of Groningen. The Chemistry Shop mediates in research for noncommercial organisations. It mainly deals with environmental topics in regard to chemical industry. Karin Ree is a Master of Environmental Chemistry, Henk Mulder obtained a doctorate in Environmental Studies in 1995. 